\title{
Caracterização de Biótipos de Arroz-Vermelho em Lavouras de ARroz no Estado do Rio Grande do SUL ${ }^{1}$
}

\author{
Characterization of Red Rice Biotypes in Rice Fields in the State of Rio Grande do Sul - Brazil
}

\author{
MENEZES, V.G. ${ }^{2}$, AGOSTINETTO, D. ${ }^{3}$, FLECK, N.G. ${ }^{4}$ e SILVEIRA, C.A. ${ }^{5}$
}

\begin{abstract}
RESUMO - O presente trabalho teve por objetivo avaliar características morfofisiológicas de alguns biótipos de arroz-vermelho ocorrentes em lavouras de arroz no Estado do Rio Grande do Sul. Para isso, conduziu-se um experimento na Estação Experimental do Arroz do Instituto Rio-Grandense do Arroz, durante a estação de crescimento 1996/97. Os tratamentos constituíram-se dos seguintes biótipos de arroz-vermelho, segundo características de grãos: grãos longo-finos, de casca clara, com ou sem arista; grãos longo-finos, de casca preta; grãos médios, de casca clara, provenientes de dois locais (Santo Antônio da Patrulha e Cachoeira do Sul); e grãos curtos, de casca clara ou de casca preta. Como padrões comparativos foram utilizados os cultivares de arroz BR-IRGA 410 e IRGA 416. As variáveis avaliadas foram: estatura de planta, afilhamento, área foliar da folha bandeira, área foliar por planta, comprimento da panícula, números de espiguetas e de grãos por panícula, esterilidade de espiguetas, relação comprimento/largura de grão, peso médio de grãos, produção de grãos por planta e germinação de sementes. Os biótipos de arroz-vermelho avaliados diferiram dos cultivares de arroz para as características morfofisiológicas investigadas. De modo geral, para essas características, não se verificaram diferenças acentuadas entre biótipos possuidores de grãos curtos, entre biótipos com grãos médios e entre aqueles com grãos longo-finos, de casca clara. Características assemelhadas de dormência apresentadas pelos biótipos de arrozvermelho com grãos longo-finos e de casca clara, com os cultivares de arroz, permitem inferir que aqueles sofreram cruzamentos com genótipos de arroz cultivado.
\end{abstract}

Palavras-chave: Oryza sativa, características morfológicas, dormência de sementes.

\begin{abstract}
This study was conducted to evaluate morphological and physiological characteristics of red rice biotypes in rice fields in the state of Rio Grande do Sul. An experiment was carried out at the Rice Experimental Station of Instituto Rio-Grandense do Arroz, during the 1996/ 1997 growing season. The treatments included the following red rice biotypes, according to their grain characteristics: fine-lengthy grains, with clear husk, with or without awn; finelengthy grains, with dark husk; medium grains, with clear husk from two locations (Santo Antônio da Patrulha and Cachoeira do Sul); short grains, with clear or dark husk. The rice cultivars BR-IRGA 410 and IRGA 417 were tested as standards. Variables evaluated were: plant height, tillering, flag-leaf area, leaf area per plant, panicle length, number of spikelets and grain per panicle, spikelet sterility, grain length/width relation, grain weight, grain yield per plant, and seed germination. The red rice biotypes evaluated differed from rice cultivars in the morphological and physiological characteristics investigated. In general, for such characteristics, there were no relevant differences between biotypes presenting short grains; between biotypes with medium grains; and between those with fine-lengthy grain and clear husk. Similar dormancy characteristics presented by red rice biotypes (with fine-lengthy grains and clear husk) and the rice cultivars allow to infer that the former underwent crossing with cultivated rice genotypes.
\end{abstract}

Key words: Oryza sativa, morphologic characteristics, seed dormancy.

1 Recebido para publicação em 17/12/2001 e na forma revisada em 7/8/2002.

2 Eng.-Agr., M.S., Pesquisador do Instituto Rio-Grandense do Arroz, Caixa Postal 29, 94930-030 Cachoeirinha-RS. ${ }^{3}$ Eng.Agr., M.S., Aluno do Programa de Pós-Graduação em Fitotecnia da Faculdade de Agronomia da UFRGS, Caixa Postal 776, 91501-970 Porto Alegre-RS, <dirceua @ vortex.ufrgs.br>. ${ }^{4}$ Eng.-Agr., Ph.D., Professor do Departamento de Plantas de Lavoura da Faculdade de Agronomia da UFRGS, Bolsista do CNPq. ${ }^{5}$ Eng.-Agr., Aluno do Programa de Pós-Graduação em Desenvolvimento Rural da UFRGS.

Planta Daninha, Viçosa-MG, v.20, n.2, p.221-227, 2002 


\section{INTRODUÇÃO}

O arroz (Oryza sativa) é um dos cereais mais cultivados no mundo, sendo considerado o alimento básico em muitos países, especialmente nos subdesenvolvidos. Dentre os fatores que limitam o potencial de rendimento da cultura do arroz no Rio Grande do Sul, destacase o arroz-vermelho (Oryza sativa). A denominação "arroz-vermelho" deve-se à coloração avermelhada do pericarpo do grão, devido ao acúmulo de tanino (Ogawa, 1992) ou de antocianina (Pantone \& Baker, 1991). A população de arroz-vermelho infestante de lavouras de arroz normalmente é constituída por vários biótipos que apresentam variação em características morfológicas. As principais características do arroz-vermelho são: ciclo mais longo e plantas de porte mais elevado do que de cultivares modernos, colmos finos, folhas de cor verde-clara e decumbentes, alto vigor e alta capacidade de afilhamento, com emissão de afilhos ontogenicamente atrasados. Por sua vez, as cariopses apresentam sementes com pericarpo de cor avermelhada, páleas e lema com variação de cor, pilosidade e aderência de páleas e lema ao pericarpo, presença ou não de arista, deiscência precoce das espiguetas e sementes com dormência (Diarra et al., 1985a; Noldin et al., 1999).

$\mathrm{O}$ arroz-vermelho costuma ser enquadrado na mesma espécie do arroz cultivado (Oryza sativa) e, devido às semelhanças morfofisiológicas entre ambos, seu controle torna-se difícil. Os efeitos negativos de sua presença em lavouras de arroz incluem competição por recursos do meio, aumento do custo de produção, acamamento de plantas, dificuldade de colheita e secagem dos grãos, depreciação da qualidade do produto, hospedagem de pragas e moléstias, diminuição do valor comercial das áreas infestadas e fonte de disseminação e reposição do banco de sementes no solo.

A redução do potencial de rendimento do arroz cultivado, causada pela interferência exercida pelo arroz-vermelho, pode inviabilizar o cultivo do cereal. Segundo Souza \& Fischer (1986), a presença de populações de arroz-vermelho que formaram 5, 55, 85 e 170 panículas $\mathrm{m}^{-2}$ reduziu o rendimento de grãos do cultivar BR-IRGA 409 em 12, 19, 36 e 50\% e do cultivar BR-IRGA 410 em 8, 20, 35 e 49\%, respectivamente. Em média, a presença de uma planta de arroz-vermelho $\mathrm{m}^{-2}$ reduz o rendimento de grãos do arroz cultivado em 2,1\% (Diarra et al., 1985a; Pantone \& Baker, 1991). Também, o número de grãos por panícula do arroz cultivado apresenta substancial decréscimo com o aumento da população de arrozvermelho, sendo reduzido em 8 e $57 \%$ para densidades de 5 e 108 plantas $\mathrm{m}^{-2}$, respectivamente (Diarra et al., 1985b).

A freqüência de cruzamentos naturais entre arroz-vermelho e cultivares comerciais de arroz varia desde menos de $1 \%$ até $52 \%$, sendo a ocorrência maior quanto mais se assemelham os ciclos dos cultivares e dos biótipos de arroz-vermelho (Langevin et al., 1990). Segundo os autores, a alta taxa de alogamia observada deveu-se à coincidência plena de floração entre o cultivar e o arroz-vermelho, bem como a uma possivel introgressão anterior de caracteres do arroz-vermelho no cultivar. Isso pode produzir descendentes com características morfofisiológicas miméticas ao arroz cultivado, aumentando ainda mais as dificuldades para se obter controle seletivo. A caracterização de diferenças entre biótipos de arrozvermelho permitirá delinear estratégias de controle, seja através de práticas culturais, sistemas de cultivo ou utilização de cultivares resistentes a herbicidas. Nesse contexto, o presente trabalho teve por objetivo avaliar características morfofisiológicas em biótipos de arroz-vermelho oriundos de lavouras de arroz no Estado do Rio Grande do Sul.

\section{MATERIAL E MÉTODOS}

O experimento foi conduzido na Estação Experimental do Arroz (EEA) do Instituto RioGrandense do Arroz (IRGA), localizada no município de Cachoeirinha-RS, durante a estação de crescimento 1996/97. A área onde foi conduzido o experimento foi previamente sistematizada através da construção de canais e drenos. A adubação de base e de cobertura, o controle de plantas daninhas (exceto arrozvermelho) e as demais práticas de manejo foram realizados de acordo com as recomendações técnicas para a cultura do arroz (Empresa...-EMBRAPA, 1999).

O delineamento experimental utilizado foi o de blocos completamente casualizados, com 
três repetições. Cada unidade experimental foi composta por seis linhas, distanciadas $16,6 \mathrm{~cm}$, totalizando uma área de $2 \mathrm{~m}^{2}(1 \times 2 \mathrm{~m})$. A semeadura foi realizada manualmente, em covas distanciadas $16,6 \mathrm{~cm}$, no dia 29/11, e a emergência ocorreu sete dias após a semeadura. Cinco dias após a emergência, realizou-se desbaste de plantas, deixando somente uma por cova.

Os tratamentos testados constaram de sete biótipos de arroz-vermelho e dois cultivares de arroz: BR-IRGA 410 e IRGA 416 (padrões comparativos) (Tabela 1). Os biótipos de arrozvermelho utilizados apresentavam as seguintes características diferenciais: grãos longo-finos, casca clara, com ou sem arista; grãos longofinos, casca preta; grãos médios, casca clara (provenientes de dois locais - Santo Antônio da Patrulha e Cachoeira do Sul); grãos curtos, casca clara; e grãos curtos, casca preta. As variáveis avaliadas foram: número de afilhos por planta aos 20, 45 e 80 dias após a emergência (DAE), área foliar da folha bandeira, área foliar por planta, estatura de planta aos 20, 50 e 80 DAE, comprimento da panícula, número de espiguetas por panícula, número de grãos cheios por panícula, esterilidade de espiguetas, relação comprimento/largura de grão, peso de 1.000 grãos e produção de grãos por planta. Em laboratório, foram realizados testes de germinação de sementes, em oito épocas (35, $55,75,95,115,135,155$ e 175 dias após a colheita).
Neste experimento, as estruturas externas páleas, lema e glumas que recobrem o endosperma e o embrião (pericarpo) foram consideradas, em seu conjunto, como casca do grão (fruto) de arroz. A área foliar, englobando a folha bandeira e a folha secundária do colmo principal e dos afilhos, foi determinada pelo produto do comprimento e da largura, corrigido pelo fator 0,71, em dez plantas da área central de cada unidade experimental. A área foliar por planta foi obtida pela soma da área foliar da folha bandeira e de quatro vezes a área foliar das folhas secundárias, multiplicada pelo número de afilhos. Em todas as épocas de realização do teste de germinação utilizou-se papel tipo germiteste, e a metodologia seguiu as recomendações das Regras para Análise de Sementes (BRASIL, 1992), diferindo apenas quanto ao número de sementes por repetição ( 4 x 25, em vez de $4 \times 100$ ). A câmara de crescimento foi regulada à temperatura de $25 \pm$ $2{ }^{\circ} \mathrm{C}$, sendo a avaliação realizada dez dias após a instalação, para todas as épocas.

Aos resultados obtidos aplicou-se análise de variância através do teste F. Constatandose significância estatística, os tratamentos foram agrupados de acordo com as características de grãos e comparados por meio de contrastes ortogonais, a 5\% de probabilidade (Tabela 1). Para germinação de sementes aplicou-se análise de regressão a 5\% de probabilidade, ajustando-se os dados aos modelos linear e quadrático.

Tabela 1 - Coeficientes dos contrastes ortogonais testados para biótipos de arroz-vermelho e cultivares de arroz

\begin{tabular}{|c|c|c|c|c|c|c|c|c|}
\hline \multirow{2}{*}{ Tratamento } & \multicolumn{8}{|c|}{ Contraste } \\
\hline & $\mathrm{C}_{1}$ & $\mathrm{C}_{2}$ & $\mathrm{C}_{3}$ & $\mathrm{C}_{4}$ & $\mathrm{C}_{5}$ & $\mathrm{C}_{6}$ & $\mathrm{C}_{7}$ & $\mathrm{C}_{8}$ \\
\hline \multicolumn{9}{|l|}{ Biótipos de arroz-vermelho: } \\
\hline 1. Grãos longo-finos, casca clara, sem arista & + & + & + & + & + & & & \\
\hline 2. Grãos longo-finos, casca clara, com arista & + & + & + & + & - & & & \\
\hline 3. Grãos longo-finos, casca preta & + & + & + & - & & & & \\
\hline \multicolumn{9}{|l|}{ Grãos médios, casca clara: } \\
\hline 4. Santo Antônio da Patrulha & + & + & - & & & + & & \\
\hline 5. Cachoeira do Sul & + & + & - & & & - & & \\
\hline 6. Grãos curtos, casca clara & + & - & & & & & + & \\
\hline 7. Grãos curtos, casca preta & + & - & & & & & - & \\
\hline \multicolumn{9}{|l|}{ Cultivares de arroz: } \\
\hline 8. BR-IRGA 410 & - & & & & & & & + \\
\hline 9. IRGA 416 & - & & & & & & & - \\
\hline
\end{tabular}




\section{RESULTADOS E DISCUSSÃO}

Para as variáveis número de afilhos por planta, nas três épocas de avaliação, e área foliar da folha bandeira, não se detectou significância estatística em nenhum dos contrastes analisados (Tabela 2), o que pode ser atribuído, em parte, ao sistema de semeadura em covas, que propiciou maior eqüidistância entre plantas e permitiu que os genótipos apresentassem valores equivalentes para essas variáveis. No entanto, trabalhos referidos na literatura relatam existir variação no número de afilhos entre biótipos de arroz-vermelho e cultivares de arroz. Nesse sentido, Diarra et al. (1985a) verificaram que biótipos de arroz-vermelho apresentaram maior número de afilhos, comparativamente aos cultivares-padrão. Também, Noldin et al. (1999) constataram que biótipos de arroz-vermelho produziram, em média, $42 \%$ mais afilhos do que cultivares de arroz. Entretanto, Know et al. (1992) observaram que o número de colmos por área produzidos por arroz-vermelho foi maior aos $20 \mathrm{DAE}$ e não apresentou diferença aos 80 DAE, em comparação a cultivares de arroz.

Para área foliar por planta, a análise de contrastes mostrou diferenças para biótipos de arroz-vermelho x cultivares de arroz; biótipos com grãos longo-finos, de casca clara $\mathrm{x}$ biótipo com grãos longo-fino, de casca preta; e entre biótipos com grãos longo-finos, diferindo quanto à presença de arista (Tabela 2). Todavia, resultados do presente experimento diferem em parte dos observados por Noldin et al. (1999), os quais verificaram que os cultivares apresentaram, em média, 26\% mais área foliar do que biótipos de arroz-vermelho. A diferença verificada entre resultados pode incluir variações nos genótipos testados e no método de determinação da variável.

A estatura de planta apresentou diferenças nas três épocas de avaliação $(20,50$ e 80 DAE) para os seguintes contrastes comparados: biótipos de arroz-vermelho x cultivares de arroz; biótipos com grãos longo-finos $\mathrm{x}$ biótipos com grãos médios; e biótipos com grãos longo-finos de casca clara $\mathrm{x}$ biótipo de grãos longo-finos, de casca preta (Tabela 2). Os contrastes envolvendo biótipos de arroz-vermelho com grãos longo-finos e grãos médios x biótipos com grãos curtos diferiram apenas aos 20 e 80 DAE. Também se constatou diferença aos 80 DAE entre biótipos de arroz-vermelho com grãos curtos e, aos 20 DAE, entre cultivares de arroz. Conforme foi relatado por Know et al. (1992),

Tabela 2 - Médias das variáveis de biótipos de arroz-vermelho e cultivares de arroz e significância dos contrastes ortogonais testados

\begin{tabular}{|c|c|c|c|c|c|c|c|c|}
\hline \multirow[b]{2}{*}{ Variável avaliada } & \multicolumn{8}{|c|}{ Contraste ortogonal } \\
\hline & $\begin{array}{c}\mathrm{C}_{1} \\
(1 \mathrm{a} 7) \text { vs. }(8+9)\end{array}$ & \begin{tabular}{|c|c}
$\mathrm{C}_{2}$ \\
(1 a 5) vs. $(6+7)$
\end{tabular} & \begin{tabular}{|c|}
$\mathrm{C}_{3}$ \\
(1 a 3$)$ vs. $(4+5)$ \\
\end{tabular} & \begin{tabular}{|c|}
$\mathrm{C}_{4}$ \\
$(1+2)$ vs. (3) \\
\end{tabular} & $\begin{array}{c}\mathrm{C}_{5} \\
(1 \text { vs. } 2) \\
\end{array}$ & $\begin{array}{c}\mathrm{C}_{6} \\
\text { (4 vs. } 5) \\
\end{array}$ & $\begin{array}{c}\mathrm{C}_{7} \\
\text { (6 vs. } 7) \\
\end{array}$ & $\begin{array}{c}\mathrm{C}_{8} \\
\text { (8 vs. } 9) \\
\end{array}$ \\
\hline \multirow{2}{*}{ Afilhos $\left(n^{o}\right.$ planta $\left.^{-1}\right)-20 \mathrm{DAE}^{1 /}$} & $2,3^{2 /}$ & $2,3^{\underline{2} \prime}$ & $2,1^{\frac{2}{}}$ & $2,0^{2 /}$ & $2,2^{2 /}$ & $2,3^{2 /}$ & $2,8^{2 !}$ & $1,8^{\frac{2}{}}$ \\
\hline & 2,2 & 2,5 & 2,4 & 2,3 & 1,8 & 2,5 & 2,2 & 2,5 \\
\hline \multirow{2}{*}{ Afilhos $\left(n^{\circ}\right.$ planta $\left.^{-1}\right)$ - 45 DAE } & $10,7^{2 !}$ & $10,5^{2 !}$ & $11,5^{2 !}$ & $11,0^{2 \prime}$ & $12,7^{2 !}$ & $8,1^{\frac{2}{2}}$ & $11,7^{2 !}$ & $10,7^{2 !}$ \\
\hline & 9,8 & 11,3 & 8,9 & 12,6 & 9,3 & 9,7 & 10,8 & 8,9 \\
\hline \multirow{2}{*}{ Afilhos $\left(n^{-}\right.$planta $\left.^{-1}\right)-80$ DAE } & $10,3^{2 !}$ & $10,2^{2 !}$ & $11,1^{\frac{2}{} l}$ & $10,9^{2 \prime}$ & $11,9^{\underline{2} !}$ & $8,2^{-1}$ & $10,2^{\underline{2} !}$ & $9,1^{\underline{2}}$ \\
\hline & 8,7 & 10,5 & 8,7 & 11,5 & 9,9 & 9,2 & 10,8 & 8,3 \\
\hline \multirow{2}{*}{ Área foliar da folha bandeira $\left(\mathrm{cm}^{2}\right)$} & $33,0^{2 \prime}$ & $32,0^{2 !}$ & $31,4^{2 !}$ & $29,8^{2 !}$ & $30,8^{2 !}$ & $34,7^{2 !}$ & $31,3^{2 !}$ & $26,1^{2 !}$ \\
\hline & 26,9 & 35,4 & 33,0 & 34,5 & 28,8 & 31,3 & 39,5 & 27,7 \\
\hline \multirow{2}{*}{ Área foliar $\left(\mathrm{cm}^{2}\right.$ planta $\left.^{-1}\right)$} & $1857^{*}$ & $1797^{\text {ns }}$ & $1824^{\text {ns' }}$ & $1650^{*}$ & $1954^{*}$ & $1738^{\text {ns }}$ & $1901^{\text {ns' }}$ & $1472^{\mathrm{ns}}$ \\
\hline & 1245 & 2009 & 1756 & 2172 & 1346 & 1773 & 2117 & 1019 \\
\hline \multirow{2}{*}{ Estatura $(\mathrm{cm})-20$ DAE } & $27,8^{*}$ & $26,9 *$ & $24,8^{*}$ & $23,4^{*}$ & $24,7^{\mathrm{ns}}$ & $28,8^{\mathrm{ns}}$ & $31,3^{\mathrm{ns}}$ & $20,9^{*}$ \\
\hline & 23,7 & 29,6 & 30,1 & 27,5 & 22,1 & 31,5 & 28,6 & 26,5 \\
\hline \multirow{2}{*}{ Estatura $(\mathrm{cm})-50$ DAE } & $64,0^{*}$ & $63,3^{\text {ns }}$ & $59,0 *$ & $55,7 *$ & $56,0^{\mathrm{ns}}$ & $70,6^{\mathrm{ns}}$ & $65,6^{\mathrm{ns}}$ & $53,0^{\mathrm{ns}}$ \\
\hline & 54,8 & 65,6 & 69,8 & 65,5 & 55,3 & 68,9 & 65,8 & 56,5 \\
\hline \multirow{2}{*}{ Estatura $(\mathrm{cm})-80 \mathrm{DAE}$} & $123,0^{*}$ & $118,6^{*}$ & $104,8^{*}$ & $97,8^{*}$ & $96,1^{\mathrm{ns}}$ & $144,3^{\text {ns }}$ & $128,0^{*}$ & $89,7^{\mathrm{ns}}$ \\
\hline & 89,5 & 133,9 & 139,2 & 119,0 & 99,4 & 134,2 & 139,7 & 89,3 \\
\hline
\end{tabular}

${ }^{1 /}$ Dias após a emergência; ${ }^{2 /}$ Não apresentou significância estatística pelo teste $\mathrm{F}$; * ou ${ }^{\mathrm{ns}}$ Contrastes significativos e não-significativos, respectivamente, a $5 \%$ de probabilidade. 
aos 60 DAE plantas de arroz-vermelho apresentaram estatura 46 e $55 \%$ superior à dos cultivares Newbonnet e Lemont. De mesmo modo, Noldin et al. (1999) e Oard et al. (2000) verificaram, respectivamente, estaturas 31 e $26 \%$ superiores em plantas de biótipos de arroz-vermelho, comparativamente aos cultivares-padrão.

A variável comprimento de panícula mostrou diferenças significativas para os contrastes entre biótipos de arroz-vermelho x cultivares de arroz; biótipos de arroz-vermelho de grãos curtos, diferindo na coloração da casca; e entre os dois cultivares de arroz (Tabela 3). Por sua vez, o número de espiguetas por panícula apresentou diferenças para os contrastes biótipos de arroz-vermelho x cultivares de arroz; biótipos com grãos longo-finos, de casca clara $x$ biótipo com grãos longo-finos, de casca preta; e entre os cultivares de arroz (Tabela 3). Para o número de grãos por panícula, o único contraste significativo ocorreu na comparação entre biótipos de arroz-vermelho x cultivares de arroz. De forma semelhante, Diarra et al. (1985a) e Noldin et al. (1999) constataram que cultivares de arroz apresentaram produção de grãos por panícula superior à do arroz-vermelho. No que se refere à esterilidade de espiguetas, os contrastes significativos incluíram as comparações biótipos de arroz-vermelho $\mathrm{x}$ cultivares de arroz; biótipos com grãos longofinos $\mathrm{x}$ biótipos com grãos médios; e biótipos com grãos médios, com origem diferente.

A relação comprimento/largura de grão foi significativa para a maioria das comparações, à exceção daquelas que incluíram biótipos de grãos médios, originados de locais diferentes; biótipos de grãos longo-finos, de casca clara, diferindo quanto à presença de arista; e entre biótipos de grãos curtos, diferindo na coloração da casca (Tabela 3 ).

No caso da variável peso do grão, todos os contrastes comparados apresentaram-se diferentes (Tabela 3), o que demonstra existir grande variabilidade entre biótipos de arrozvermelho para essa característica. Esses resultados não coincidem totalmente com os observados por Noldin et al. (1999), em que os autores verificaram que, dos 19 biótipos estudados, 14 apresentaram peso médio de grão dentro do intervalo de peso para os três cultivares-padrão avaliados. Em relação à produção de grãos por planta, constatou-se significância para os seguintes contrastes: biótipos de arrozvermelho $\mathrm{x}$ cultivares de arroz; biótipos com grãos longo-finos e grãos médios $\mathrm{x}$ biótipos com grãos curtos; biótipos com grãos longo-finos, de casca clara, diferindo quanto à presença de arista; e entre os cultivares de arroz (Tabela 3).

Tabela 3 - Médias das variáveis de biótipos de arroz-vermelho e cultivares de arroz e significância dos contrastes ortogonais testados

\begin{tabular}{|c|c|c|c|c|c|c|c|c|}
\hline \multirow[b]{2}{*}{ Variável avaliada } & \multicolumn{8}{|c|}{ Contraste ortogonal } \\
\hline & $\begin{array}{c}\mathrm{C}_{1} \\
(1 \mathrm{a} 7) \text { vs. }(8+9)\end{array}$ & $\begin{array}{c}\mathrm{C}_{2} \\
(1 \mathrm{a} 5) \text { vs. }(6+7)\end{array}$ & \begin{tabular}{|c|c|}
$\mathrm{C}_{3}$ \\
$(1 \mathrm{a} 3)$ vs. $(4+5)$
\end{tabular} & $\begin{array}{c}\mathrm{C}_{4} \\
(1+2) \text { vs. (3) }\end{array}$ & $\begin{array}{c}\mathrm{C}_{5} \\
\text { (1 vs. 2) }\end{array}$ & $\begin{array}{c}\mathrm{C}_{6} \\
\text { (4 vs. 5) }\end{array}$ & $\begin{array}{c}\mathrm{C}_{7} \\
\text { (6 vs. 7) }\end{array}$ & $\begin{array}{c}\mathrm{C}_{8} \\
\text { (8 vs. 9) }\end{array}$ \\
\hline \multirow{2}{*}{ Comprimento de panícula $(\mathrm{cm})$} & $20,5^{*}$ & $20,4^{\mathrm{ns}}$ & $20,5^{\mathrm{ns}}$ & $20,4^{\mathrm{ns}}$ & $20,1^{\mathrm{ns}}$ & $20,7^{\mathrm{ns}}$ & $20,0^{*}$ & $25,0^{*}$ \\
\hline & 23,3 & 20,8 & 20,2 & 20,6 & 20,7 & 19,7 & 21,7 & 21,6 \\
\hline \multirow{2}{*}{ Espiguetas $\left(\mathrm{n}^{\underline{0}}\right.$ panícula $\left.^{-1}\right)$} & $96,2^{*}$ & $98,5^{\text {ns }}$ & $99,7^{\mathrm{ns}}$ & $107,8^{*}$ & $116^{\mathrm{ns}}$ & $105^{\mathrm{ns}}$ & $92^{\text {ns }}$ & $160^{*}$ \\
\hline & 114,3 & 90,4 & 96,7 & 83,5 & 100 & 89 & 88 & 129 \\
\hline \multirow{2}{*}{ Grãos $\left(\mathrm{n}^{\mathrm{o}}\right.$ panícula $\left.^{-1}\right)$} & $56,6^{*}$ & $57,7^{\mathrm{ns}}$ & $62,5^{\text {ns }}$ & $66,6^{\text {ns }}$ & $72^{\mathrm{ns}}$ & $62^{\text {ns }}$ & $56^{\mathrm{ns}}$ & $121^{\mathrm{ns}}$ \\
\hline & 114,0 & 53,8 & 50,5 & 54,1 & 62 & 39 & 51 & 107 \\
\hline \multirow{2}{*}{ Esterilidade de espiguetas (\%) } & $41,7 *$ & $41,9^{\mathrm{ns}}$ & $37,1^{*}$ & $37,9^{\mathrm{ns}}$ & $38,1^{\mathrm{ns}}$ & $42,1 *$ & $39,2^{\mathrm{ns}}$ & $24,2^{\mathrm{ns}}$ \\
\hline & 20,9 & 41,1 & 49,2 & 35,5 & 37,7 & 56,3 & 43,0 & 17,5 \\
\hline \multirow{2}{*}{ Relação comprimento/largura de grão } & $2,4^{*}$ & $2,6^{*}$ & $2,9^{*}$ & $3,0^{*}$ & $3,0^{\mathrm{ns}}$ & $2,1^{\mathrm{ns}}$ & $2,0^{\mathrm{ns}}$ & $3,3^{*}$ \\
\hline & 3,4 & 2,0 & 2,1 & 2,6 & 3,0 & 2,1 & 2,0 & 3,5 \\
\hline \multirow{2}{*}{ Peso de grão (g x 1.000) } & $29,1 *$ & $28,3^{*}$ & $27,6^{*}$ & $25,8^{*}$ & $26,5^{*}$ & $29,9 *$ & $32,1^{*}$ & $25,5^{*}$ \\
\hline & 25,2 & 31,0 & 29,4 & 31,3 & 25,1 & 28,8 & 29,9 & 25,0 \\
\hline \multirow{2}{*}{ Produção de grãos (g planta $\left.{ }^{-1}\right)$} & $17,3^{*}$ & $18,4^{*}$ & $18,6^{\mathrm{ns}}$ & $18,5^{\text {ns }}$ & $21,8^{*}$ & $18,6^{\mathrm{ns}}$ & $12,0^{\mathrm{ns}}$ & $27,8^{*}$ \\
\hline & 24,6 & 14,5 & 18,2 & 18,7 & 15,3 & 17,7 & 16,9 & 21,4 \\
\hline
\end{tabular}

$*$ ou ${ }^{\text {ns }}$ Contrastes significativos e não-significativos, respectivamente, a $5 \%$ de probabilidade. 
A análise de regressão para germinação de sementes dos cultivares de arroz não foi significativa para os modelos testados (Figura 1). Esses cultivares, desde o início dos testes, apresentaram germinação elevada, demonstrando ausência de dormência. Para germinação dos biótipos de arroz-vermelho com grãos longofinos, de casca clara, independentemente da presença ou não de arista, os dados ajustaramse satisfatoriamente ao modelo quadrático. Nos outros cinco biótipos o ajuste foi linear. A comparação estatística entre as equações lineares não indicou diferenças significativas entre elas (Zar, 1996). Desse modo, os biótipos de arrozvermelho com grãos curtos ou médios, independentemente da cor da casca ou da origem, e o biótipo de grãos longo-finos, de casca preta, apresentam niveis equivalentes de dormência e de liberação para germinação. Nesse sentido, Oard et al. (2000) detectaram maior nivel de dormência em biótipos de arroz-vermelho, comparativamente aos cultivares-padrão, em teste que realizaram logo após a colheita. No entanto, esses autores já não constataram diferença na germinação dos biótipos oito semanas após a colheita das sementes.
Os baixos níveis de dormência inicial verificados nos biótipos de arroz-vermelho com grãos longo-finos e de casca clara, em relação aos demais, comprovam a hipótese, também apontada por outros autores, de que biótipos possuidores de grãos longo-finos resultam de cruzamentos com cultivares de arroz de grãos longos e finos (Marques et al., 1983; Pedroso, 1985). A duração e a intensidade da dormência variam em função do biótipo e, também, dependem das condições do ambiente durante o desenvolvimento das sementes (Delatorre, 1999). Ainda segundo esse autor, a maior parte dos biótipos de arroz-vermelho apresenta dois tipos de dormência: um devido às estruturas envoltórias das sementes e outro devido à incapacidade de o embrião germinar, o qual vai sendo reduzido com o tempo pós-colheita.

As diferenças verificadas entre biótipos de arroz-vermelho para as várias características avaliadas demonstram existir grande variabilidade genética entre genótipos, a qual apresenta relevância para a persistência de sementes de arroz-vermelho no solo e para sua adaptação e sobrevivência no meio. Dessa forma, o controle do arroz-vermelho com base em práticas

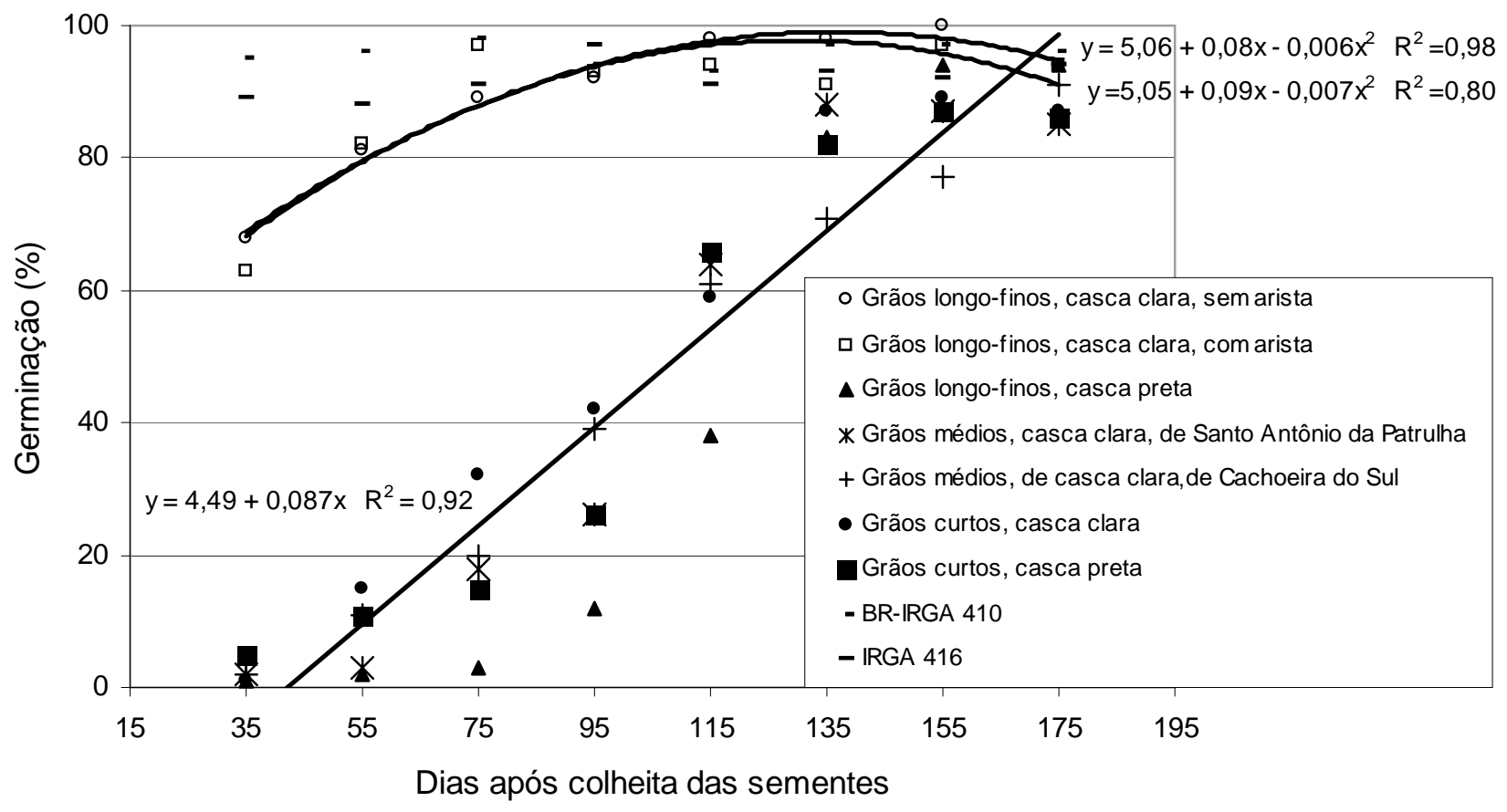

Figura 1 - Linhas de tendência e equações de regressão para germinação de sementes de biótipos de arroz-vermelho e cultivares de arroz. 
de manejo ou a supressão de seu desenvolvimento através da utilização de cultivares de arroz portadores de maior habilidade competitiva tornam-se duvidosos e de curta viabilidade de uso. Outro ponto a destacar refere-se à inexistência de trabalhos que busquem classificar, através de características genéticas, os biótipos de arroz-vermelho ocorrentes em lavouras arrozeiras do Brasil. Em pesquisa realizada nos Estados Unidos com esse objetivo, constatou-se que os biótipos de arrozvermelho tradicionalmente classificados como Oryza sativa spp. indica pertenciam não apenas a esta, mas também incluíam as espécies Oryza sativa spp. japonica, Oryza rufipogon e Oryza nivara (Vaughan et al., 2001). A correta identificação das espécies infestantes, particularmente biótipos de arroz-vermelho, é pressuposto fundamental para elaboração de estratégias de controle que sejam eficazes e de longa duração.

Em decorrência dos resultados obtidos, pode-se concluir que alguns biótipos de arrozvermelho encontrados em áreas de arroz do Rio Grande do Sul mostram diferenças em características morfofisiológicas dos cultivares de arroz. De modo geral, poucas características diferenciais separam biótipos possuidores de grãos curtos; aqueles de grãos médios oriundos de dois locais; ou, ainda, os de grãos longo-finos, de casca clara. As características assemelhadas de dormência apresentadas pelos biótipos de arroz-vermelho de grãos longo-finos e de casca clara com os cultivares-padrão de arroz permitem inferir que aqueles sofreram cruzamentos com genótipos cultivados de arroz.

\section{LITERATURA CITADA}

BRASIL. Ministério da Agricultura e Reforma Agrária. Coordenação de Laboratório Vegetal. Regras para análise de sementes. Brasília: 1992. 365 p.

DELATORRE, C. A. Dormência em sementes de arroz vermelho. Ci. Rural, v. 29, n. 3, p. 565-571, 1999.

DIARRA, A.; SMITH Jr., R. J.; TALBERT, R. E. Growth and morphological characteristics of red rice (Oryza sativa) biotypes. Weed Sci., v. 33, n. 3, p. 310-314, 1985a.
DIARRA, A.; SMITH Jr., R. J.; TALBERT, R. E. Interference of red rice (Oryza sativa) with rice (Oryza sativa). Weed Sci., v. 33, n. 5, p. 644-649, 1985b.

EMPRESA BRASILEIRA DE PESQUISA AGROPECUÁRIA - EMBRAPA - Embrapa Clima Temperado. Arroz irrigado: recomendações técnicas da pesquisa para o Sul do Brasil. Pelotas: 1999. 124 p. (Documento, 57).

KWON, S. L.; SMITH JR., R. J.; TALBERT, R. E. Competitive growth and development of red rice (Oryza sativa) and rice (O. sativa). Weed Sci., v. 40, n. 1, p. 57-62, 1992.

LANGEVIN, A. S.; CLAY, K.; GRACE, J. B. The incidence and effects of hybridization between cultivated rice and its related weed rice (Oryza sativa L.). Evolution, v. 44 , n. 4 , p. $1000-1008,1990$.

MARQUES, L. F. et al. Arroz vermelho e cultivado, na produção de sementes. Lav. Arroz., v. 36, n. 345, p. 3-6, 1983.

NOLDIN, J. A.; CHANDLER, J. M.; McCAULEY, G. N. Red rice (Oryza sativa) biology. I. Characterization of red rice ecotypes. Weed Technol., v. 13, n. 1, p. 12-18, 1999.

OARD, J. et al. Field evaluation of seed production, shattering, and dormancy in hybrid populations of transgenic rice (Oryza sativa) and the weed, red rice (Oryza sativa). Plant Sci., v. 157, n. 1, p. 13-22, 2000.

OGAWA, M. Red rice. Chemistry and organisms, v. 30, n. 6, p. 385-388, 1992.

PEDROSO, B. A. Biologia e importância do arroz vermelho. Lav. Arroz., v. 38, n. 359, p. 37-38, 1985.

PANTONE, D. J.; BAKER, J. B. Reciprocal yield analysis of red rice (Oryza sativa) competition in cultivated rice. Weed Sci., v. 39, n. 1, p. 42-47, 1991.

SOUZA, P. R.; FISCHER, M. M. Arroz vermelho: danos causados à lavoura gaúcha. Lav. Arroz., v. 39, n. 368, p. 19-20, 1986.

VAUGHAN, L. K. et al. Is all red rice found in commercial rice really Oryza sativa? Weed Sci., v. 49, n. 3, p. 468-476, 2001.

ZAR, J. H. Biostatistical analysis. London: Prentice-Hall International, 1996. p. 353-361. 